\title{
Educational Program Using the Impacts of Animation on the Perceptionand Motor Skill in Learning the Front Straight Strike Skill in Tennisfor Children from 9 to 11 Years
}

\author{
Suzan Moustafa Metwally Ismail*, Maha Ibrahim Ahmed Othman**
}

\begin{abstract}
:
The research aims to build an educational animated program and identify its impact on both perception and motor skill learning hit the front straight in tennis for children (9-11 years) And find a correlation between perception and motor skill learning, the experimental method was used in two groups, one experimental strength (18) children was applied using the tutorial animation on them, And the other officer strength (17) children, the traditional method was used to learn the skill of the strike the front straight with them, Research tools included on the physical abilities test, a test scenario to motor skill strike the front straight in tennis, an evaluation form performance skills of the skill (under discussion), Tutorial using animation, and the results showed that the use of animated tutorial more positive than the traditional method used in both perception and motor skill learning hit the front straight in tennis.
\end{abstract}

\section{Problem of the study and its importance:}

The world today is rapidly changing and the scientific and technical revolution led to change the concept of modern education, and seek to develop education through its educational technology and technical means to deliver information and skills development in an effective way, as well as to provide a learning environment that is flexible and powerful help in the preparation of the learner and provide him with experience and skills to cope with the rapid developments for the advancement of his society on scientific basis, which all the world seeks to achieve. (34: 130)

Physical Education is one of the important areas of education, which aims to achieve balanced overall growth of the child through the attention and care of workers in the field of physical education by getting the best programs for teaching different motor skills. (2:21)

* Assistant Professor: Educational Sciences, psychological and social Department, Faculty of Physical Education for Girls, Alexandria University, Egypt.

** Ph.D.: Curriculum and Teaching Methods of Physical Education Department, Faculty of Physical Education for Girls, Alexandria University, Egypt.
The use of educational technology in the field of motor learning makes them more effective and positive, which make the learner responsible and participants and a positive to a large extent instead of being a receiver or copier, and lead to the improvement of the educational process and increase the speed becomes specifications skill more refined and polished, does not stop its role at this point but also to build and develop the basis of the educational process for a learner which is motor perception. (19: 152)

Kinetic motion vision is to see objects and phenomena reproduced in memory, which reproduce the movement a serious intellectual to deal, where the play experience mobility plays an important role in building the basis for the perception of motor skills, so you must work to fill the memory, the kinetics of the learners requirements of the correct performance of motor skills in order to build a perception of motor contributes to rais the level of performance and increase concentration and reduce stress. (11: 94)

And thus helps the perception kinetic learner to understand the nature of the movement and sequence of skills, attitudes and events associated with better performance as the 
learner becomes more aware of the requirements of successful performance. (5: 151)

The multiple uses of visualization motor in the field of education and learning help in the speed of learning motor skills and mastery, and assistance in the speed of learning plans to play, and help solve performance problems, and training session on some skills, psychological, and helping to control physiological responses, and review and analysis of performance, and improve self-confidence positive thinking, and help with the pain and speed healing after injury recovery. (21: 251-255)

The researchers will apply the first use of these uses is to help in the speed of learning motor skills and mastering it, and through an educational program to teach proposed the skill of the front straight strike of tennis.

Indicates Harris (1986) to the basic rules that must be met for successful conception motor is that the perception to be dynamic for all parts of the skill and its constituent elements with repeated retrieval until stability in the mind, is also used with the movements and only repeated and practiced the same timing or rhythm of the movement, and is used all the dimensions ofachievement and this needs to be systematic and continuous training to be more effective. (32: 56)

The researchers took in notice in the preparation of the section on perception motor and the implementation of the program modules a number of principles including the concept of mental performance and results, and attention to detail, and focus on the positives, visualization and mental skill as a whole, and the perception of mental pre-performance direct visualization and mental at the same speed performance, and for a short period. $(17: 152)$

Perception consists of two types external perception of motor used in the initial stages of learning, and the perception of an internal motor, preferably used in the stage of perfection and the installation, where the player imagines himself leading the right skill image. (5: 317318) (17: 216)

The researchers will use in building the program the first type which is the external perception and the motor is in the presentation of motor skill through an animated cartoon character for children (sample) on the display screen, for the convenience of the nature of the selected age group.

The use of modern technology in learning new motor skills, which have the ability to view the details of the movement slowly, such as the computer in addition to verbal explanations are the most important methods used to improve the perception motor. (1: 98)

The latest use of computers in teaching and learning of many of the courses a substantial improvement in the progress of learners and reducing the time required to learn both individually or groups, in addition to its use as a teacher assistant in the teaching process can be used as a model, or a stimulator of help in raising the level of learners provide them with feedback during learning as used in a variety of educational situations.(32: 9)

The animation applications, educational tools that further improve motivation and reduce the time that we need to learn effectively, which lead to fundamental changes in concepts, relationships and characteristics that give a new image to learn, as well as the importance of animation in terms of entertainment it plays a more important role in terms of educational and illustrative as it is more conductive to the content, in addition to being symbolic. (29: 16)

There are many studies that used animation to learn some motor skills, including a study Maynard (2002) (34) in handball, and the study Sassen \& Timothy (2001) (36), study of Stan Hayward Stan Hayward (2001) (37) in the basic motor skills, and study of Michel Moulin Michelle Mullen (1999) (35) year in gymnastics - artistic gymnastics - athletics.

The outcome of these studies on the positive use of animation software to learn different skills.

The tennis from the sport's most prevalent in the world, has been observed a steady increase in the number of practitioners from all classes during the last three decades, they sport enjoyable for the players and competitors alike, whereby the physical and mental fitness of the player, and one must exercise restraint, patience, with the ability to control temper, good disposition, and the speed of reactions. 
Tennis skills are divided into basic skills (all kinds of front ground strikes - all kinds of back ground strikes - all kind of serves) and advanced skills (types of air strikes - strikes brought all kinds - strikes Fallen - blows). (7: 302-305)

The researchers selected the skill of the front ground straight strike Forehand Stroke as it strikes the familiar and the most prevalent in the game of tennis, which are easy to perform, the player must learn it well and mastery and control before he start to learn any further strikes, especially for children and beginners. $(9: 51-57)$

In light of the progress in the current era, and the use of modern technology in both teaching and learning in the field of Physical Education, and the importance of computer and assist in the educational process through the different styles, which include animation, the researchers see that the educational films they implemented in a form of animation and using the computer it is possible to play an important role in the educational field, especially for children in the age group of (9:11) years.

Through the experience of one of the researchers as a parameter of children enrolled in the sport of tennis at the Faculty of Physical Education for Girls in Alexandria in the period (1992: 2007) has noted the marked reduction in the level of performance of basic skills in tennis for children during that period, despite the effort of teachers in the hierarchy education, noting that the stage is where the practice of many of the children's tennis, has attributed the researchers of this decrease in the level of skill to that felt by the children from the boredom and the dispersion of my mind as a result of the use of learning styles of traditional and non-use of modern teaching aids in the process of teaching and learning which have impact on the revitalization of the mind and raise the efficiency of the senses and increase focus, and then the high level of performance skills.

And by reference to the research and previous studies relevant to the subject it became clear that the educational programs animation did not address the area of tennis or to the importance of using computers in education and the perception of the stages of performance of a skill strike the front straight in tennis the age group of (9-11) years, in addition to what came many of the recommendations of the research programs of the importance of hiring educational animated in various sports activities including tennis.

This called for researchers to conduct this study in order to build an educational program using animation and see its impact on the perception motor and learn the skill of the strike the front straight in tennis for children (9-11 years) in an attempt to raise the level of performance skills for this population group, which is the fundamental basis for learning and Talented and the formation of teams and sports teams in the future.

\section{Research objectives:}

The research aims to:

1. Building an educational animated program and to identify the impact on each of: A. Perception of motor skill the front straight strike in tennis for children (9-11 years). B. Learn a skill the front straight strike in tennis for children (9-11 years).

2. Find a correlation between perception and motor skill learning the front straight strike in tennis for children ( 9 -11 years)

\section{Hypothesis:}

1. there are significant differences between tribal and dimensional measurements in the test scenario for the motor skill off the front straight strike in tennis for the experimental group of children (9-11 years) for dimensional measurement.

2. There are significant differences between tribal and dimensional measurements in learning a skill strike the front straight in tennis for the experimental group of children (9-11 years) for dimensional measurement. 3. There are significant differences in perception between control group and experimental groups for the experimental group.

4. There are significant differences in learning the skill of the front straight strike in tennis between experimental and control groups for the experimental group.

5. There is a positive correlation in the measurement of the dimensional perception of 
motor skill learning and the front straight strike in tennis for children (9-11 years) between the experimental and control groups.

\section{Search procedures:}

\section{Research Methodology:}

Was used experimental method using the experimental design of two experimental and one other officer to follow the tribal dimensional measurement each.

\section{Areas of research:}

\section{Spatial domain:}

The study was conducted at the Faculty of Physical Education for Girls, Alexandria University, for the following reasons:

- The availability of a tennis court.

- The availability of Data show a display device can be moved to the tennis court and a personal connection to a PC or Lab top.

\section{The time domain:}

Applied to study in the period from 14/6/2008 to $14 / 8 / 2008$ a period set for the involvement of children the club's Summer Faculty of Physical Education for Girls, Alexandria University.

\section{Research community:}

Comprised the research community (55) of boys and girls (9-11 years) were divided as follows:

- The study sample basic: strength (35) boys and girls were selected in a deliberate as representing the community total of applicants to practice tennis in the summer season (2008) Faculty of Physical Education for Girls,
Alexandria University, were divided into two groups, one experimental group (18) children, and other control group (17) children.

- Sample survey: strong (20) children were randomly selected from the same age group of participants the club's Summer in the same year, they were divided into two groups, the first group consists of (10) children who have no previous experience of the exercise of tennis to determine the suitability of the program for the research sample, The second group (10) children who have previous experience of the exercise of tennis to find a scientific transactions (validity and reliability) of the research tools.

Has been selected age group of (9-11) years as they represent one of the stages classified for the enrollment of children in schools teach the skills the Summer club's Faculty of Physical Education for Girls, Alexandria University, and is characterized by movements of the child at this stage a great deal of agility, speed, power, and timely, streamlined and good transmission movement of the trunk to the arms and legs, as the child can guidance aims to movements and the ability to control, and can predict the movements of others, and also the speed of comprehension and learning of new movements, in addition to that this phase is optimal for learning motor of the child where increasing its ability to pay attention and focus in terms of range and duration (20: 135-137).

Has been the harmonization between the total study sample in some physical measurements, and some physical abilities, perception and motor skill performance and the level of skill to hit the front straight in tennis, which is shown in Table (1) 
Table (1)

Sample homogeneity in the variables $(n=35)$

\begin{tabular}{|c|c|c|c|c|c|c|c|}
\hline \multicolumn{3}{|c|}{$\begin{array}{l}\text { Statistical treatments } \\
\text { Variables of study }\end{array}$} & Mean & S.D & $\begin{array}{l}\text { COEFFICIENT } \\
\text { KURTOSIS }\end{array}$ & $\begin{array}{l}\text { COEFFICIENT } \\
\text { SKEWNESS }\end{array}$ & t. test \\
\hline \multirow{3}{*}{ 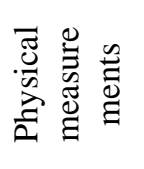 } & \multicolumn{2}{|c|}{ Age / year } & 10.315 & 0.608 & -0.462 & -1.00 & 100.284 \\
\hline & \multicolumn{2}{|c|}{ Length / cm } & 139.657 & 5.166 & 0.220 & -0.417 & 160.066 \\
\hline & \multicolumn{2}{|c|}{ Weight / kg } & 25.771 & 2.556 & 0.226 & -0.897 & 59.644 \\
\hline \multirow{4}{*}{ 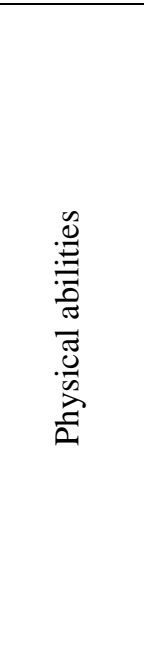 } & $\begin{array}{c}\text { distinctive } \\
\text { force of the } \\
\text { muscles of the } \\
\text { arms }\end{array}$ & $\begin{array}{c}\text { test drove } \\
\text { medical } \\
\text { Football }(1 \mathrm{~kg}) / \mathrm{m}\end{array}$ & 2.025 & 0.27 & -0.554 & 0.214 & 50.204 \\
\hline & $\begin{array}{l}\text { distinctive } \\
\text { force of the } \\
\text { muscles of } \\
\text { legs }\end{array}$ & $\begin{array}{l}\text { test the long } \\
\text { jump/m }\end{array}$ & 1.875 & 0.176 & -0.177 & -0.196 & 71.092 \\
\hline & $\begin{array}{c}\text { Bearing } \\
\text { strength of the } \\
\text { muscles of the } \\
\text { arms }\end{array}$ & $\begin{array}{l}\text { test for the } \\
\text { longest } \\
\text { time/sec. }\end{array}$ & 18.22 & 4.078 & 0.911 & 0.617 & 29.974 \\
\hline & The accuracy & $\begin{array}{l}\text { correction on } \\
\text { the number of } \\
\text { overlapping } \\
\text { circles(no./time) }\end{array}$ & 7.644 & 1.509 & -0.443 & -0.311 & 33.963 \\
\hline \multicolumn{3}{|c|}{$\begin{array}{c}\begin{array}{c}\text { Perception of motor skill strike the front } \\
\text { straight }\end{array} \\
\end{array}$} & 1.565 & 1.471 & 0.376 & -0.975 & 5.100 \\
\hline \multicolumn{3}{|c|}{$\begin{array}{l}\text { Level of performance skill to skill strike the } \\
\text { front straight }\end{array}$} & 0.695 & 0.328 & 0.043 & -1.166 & 10.166 \\
\hline
\end{tabular}

It is clear from Table (1) that all the values of the torsion is limited to transactions between the $( \pm 3)$, indicating homogeneity of values and moderation sample sizes in all variables (under discussion).

\section{Search Tools:}

1. Tests of physical abilities skillfully hit the front straight in tennis (Attachment 1).

2. Motor perception test (Attachment 2).

3. Performance evaluation form for the skill off the front straight strike in tennis (Attachment 3).

4. Skill test for the front straight strike (Attachment 4).

5. Educational program using animation (Attachment 5).

\section{Baseline study:}

Been implemented in the baseline study period (12/07/2008 to 07/08/2008) as follows:

\section{Tribal measurement:}

Measurement was conducted for two groups of tribal research (experimental and control) from (12 / 7 to $17 / 7 / 2008)$ in:

1. Perception test motor skill to strike the front straight, after giving a general idea of the skill by verbal explanations, and then take the test.

2. Skills test performance to the skill off the front straight strike after the form is displayed for optimal performance supported by verbal explanation, and testing, has been added to by three judges who teaching tennis at the Faculty of Physical Education for Girls, Alexandria University.

\section{Implementation of the program:}

Program was implemented on the children of the two groups (experimental and control) from (19 / 7 to 31/7/2008) with three lessons a week during class (90) minutes, to be teaching for the two interchangeably during the days of the week in the same field and same time of (9 to 10.30) in the morning. 


\section{Dimensional measurement:}

Dimensional measurement was performed for the two sets of research in the period from $(2 / 8$ to $07 / 08 / 2008$ ) in:

1. Perception test and motor skill displayed after the front straight strike style animation directly. 2. Test performance skills for the skill of the front straight strike, through the use of the judges the same rate.

\section{Treatment period:}

- The mean - standard deviation.

- T-Test for significant differences - quarters, the highest and lowest.

- Correlation coefficient of the percentage of improvement.

- Coefficient of the torsion coefficient Splaying.

\section{Presentation and discussion of results:}

Will be presented and discussed results to validate the hypotheses.

\section{First hypothesis:}

There are significant differences between tribal and dimensional measurements in the test scenario for the motor skill off the front straight strike in tennis for the experimental group of children (9-11 years) for dimensional measurement.

To validate the first hypothesis was to find differences between the average measurements of tribal and dimensional visualization in the test motor skill to hit the front straight strike in tennis for the children of the experimental group and is shown by Table (2)

Table (2)

Differences between the average measurements of tribal and dimensional visualization in the test motor Skill to strike the front straight in tennisfor the children of the experimental group $(n=18)$

\begin{tabular}{|c|c|c|c|c|c|c|}
\hline \multirow{2}{*}{$\begin{array}{c}\text { Statistical } \\
\text { treatments } \\
\text { Perception motor } \\
\text { test }\end{array}$} & \multicolumn{2}{|c|}{ measurement tribal } & \multicolumn{2}{|c|}{$\begin{array}{l}\text { dimensional } \\
\text { measurement }\end{array}$} & \multirow{2}{*}{$\begin{array}{c}(\mathrm{T}) \\
\text { value }\end{array}$} & \multirow{2}{*}{$\begin{array}{l}\text { the percentage of } \\
\text { improvement } \%\end{array}$} \\
\hline & Mean & S.D & Mean & S.D & & \\
\hline (1) Image & 0.326 & 0.654 & 1.937 & 0.521 & 7.97 & $494.17 \%$ \\
\hline (2) Image & 0.257 & 0.675 & 1.458 & 1.124 & 3.788 & $467.31 \%$ \\
\hline (3) Image & 0.458 & 0.802 & 1.746 & 0.931 & 4.336 & $281.12 \%$ \\
\hline (4) Image & 0.164 & 0.569 & 1.359 & 0.976 & 4.377 & $728.65 \%$ \\
\hline (5) Image & 0.339 & 0.743 & 1.832 & 0.823 & 5.570 & $440.41 \%$ \\
\hline $\begin{array}{c}\text { The total test (10) } \\
\text { degrees }\end{array}$ & 1.544 & 1.253 & 8.332 & 1.651 & 11.378 & $346.39 \%$ \\
\hline
\end{tabular}

Value $(T)$ Indexed at level of significance at $0.05=2.11$, at $0.01=2.90$

It is clear from Table (2) the existence of statistically significant differences at the level of significance $(0.05)$ for telemetric in the test scenario of the front straight strike skill ranged value $(\mathrm{T})$ between $(3.788,7.97)$ for the stages of the performance of skill and (11.378) of the skill as a whole, as the percentage of improvement ranged between $(281.12 \%, 728.65 \%)$ of the stages of skill performance, and (346.39\%) of the skill as a whole.

Have attributed the researchers of this improvement to the application of the educational program proposed, it is by watching the children of the character animation and the use of the sense of sight when you see the animation program were able to visualize stages of the performance of a strike skill the front straight well, and to answer the test scenario kinetic skill better in telemetric for measurement of tribal.

This finding corresponds with the assertion of (4), (17), (21), I have to imagine motor is the reflection of objects and aspects of the above individual awareness, and visualization mental process using the senses in the performance and function to achieve the process of perception.

Also confirmed the results of both studies (3) (10) (13) (26) (27) on the perception that the high level of motor and mental development of psychomotor skills in various sports activities help increase learning speed and accuracy of the performance of these skills. 
The display of motor skills and stages of multiuse animation helped to understand the children for a few minutes and motor skill sequence of stages, all of which help to recall the image of the right motor skill, which helped to improve the perception motor.

This is what made the researcher to use the children sense of sight research (sample) to see the animation program proposed for the skill (under discussion), which led to conceive the child of the stages of this skill efficiently.

And thus achieved the first hypothesis of the research

\section{The second hypothesis:}

There are significant differences between tribal and dimensional measurements in learning a skill strike the front straight in tennis for the experimental group of children (9-11 years) for dimensional measurement.

To investigate the validity of the second hypothesis was to find the difference between the average tribal and dimensional measurements in the test performance to the front straight strike skill in tennis for the children of the experimental group and is shown by Table (3)

Table (3)

The difference between the average measurements of tribal and post test performance skills in the front straight Strike skill in tennis for children of the experimental group $(n=18)$

\begin{tabular}{|c|c|c|c|c|c|c|}
\hline \multirow{2}{*}{$\begin{array}{c}\text { Statistical treatments } \\
\text { Skill }\end{array}$} & \multicolumn{2}{|c|}{ measurement tribal } & \multicolumn{2}{|c|}{$\begin{array}{l}\text { dimensional } \\
\text { measurement }\end{array}$} & \multirow{2}{*}{$\begin{array}{c}(\mathrm{T}) \\
\text { value }\end{array}$} & \multirow{2}{*}{$\begin{array}{l}\text { the percentage } \\
\text { of } \\
\text { improvement } \%\end{array}$} \\
\hline & Mean & S.D & Mean & S.D & & \\
\hline $\begin{array}{l}\text { Performance skills for } \\
\text { skill hit the front straight }\end{array}$ & 2.423 & 0.614 & 8.203 & 0.808 & 23.495 & $238.547 \%$ \\
\hline
\end{tabular}

It is clear from Table (3) that the level of skill performance to the front straight Strike skill is significant at the level of (0.01) for telemetric, and the percentage of improvement of $238.547 \%$, which confirms the positive impact of the animation program on the skill performance where he helped the use of the means of education and modern technology in speed of learning and performance skill, and that by watching and motor skill performed by cartoon character within the program and also listen to verbal explanations of the skill.

This is consistent with the assertion of (16), (21)), 33), and demonstrated the results of studies of (6), (8), (23), (34) that use animation program a positive impact and highly effective in learning and performance of motor skills for various sports activities. This achieves the second hypothesis of the research

\section{The third hypothesis:}

"There are significant differences in perception between motor control and experimental groups for the experimental group."

To investigate the third hypothesis was to find the arithmetic mean, standard deviation and the value of $(T)$ of the tribal and dimensional visualization of the test motor skill to hit the front straight in tennis for the two experimental and control group and shown by the table (4)

Table (4)

The differences between tribal and dimensional measurements of the control and experimental groups in the perception motor test

\begin{tabular}{|c|c|c|c|c|c|}
\hline \multirow{3}{*}{ Statistical treatmentsgroups } & \multicolumn{4}{|c|}{ perception motor test } & \multirow{3}{*}{$\begin{array}{c}(\mathrm{T}) \\
\text { value }\end{array}$} \\
\hline & \multicolumn{2}{|c|}{ measurement tribal } & \multicolumn{2}{|c|}{$\begin{array}{c}\text { dimensional } \\
\text { measurement }\end{array}$} & \\
\hline & Mean & S.D & Mean & S.D & \\
\hline $\begin{array}{l}\text { The experimental group } \\
\qquad(\mathrm{n}=18)\end{array}$ & 1.544 & 1.253 & 8.332 & 1.651 & 15.809 \\
\hline $\begin{array}{l}\text { The control group } \\
(\mathrm{n}=17)\end{array}$ & 0.413 & 0.193 & 7.043 & 0.486 & 35.693 \\
\hline
\end{tabular}

motor perception between the experimental and It is clear from Table (4) the existence of control groups for the experimental group. statistically significant differences at the level of 0.01 for dimensional measurement in the test 
(13), (22). And confirms the third hypothesis of research.

\section{The fourth hypothesis:}

There are significant differences in learning front straight strike skill in tennis between experimental and control groups for the experimental group.

To investigate the validity of the fourth hypothesis was the opinion of the use of three judges who taught tennis in the evaluation of faculty (research sample) in the control and experimental skill (under discussion), which is shown in Table (5)
And returns the researchers improved the results of the experimental group to use the educational program proposed by the cartoon character to perform the skill, as well as differing views between the slow and fast which helped to attract the attention of children and helped them to imagine kinetic proper skill, leading to improved performance skills in an easy and clear, and has two attractions and the thrill of skill (under discussion), raising children motivated to learn and push them to do more and not feel bored during learning. This is consistent with the results of both studies (10),

Table (5)

Differences between the average measurement of the dimensional control and experimental groups in the front straight Strike skill in tennis, according to the opinion of judges

\begin{tabular}{|c|c|c|c|c|c|}
\hline \multirow{2}{*}{$\begin{array}{c}\text { Statistical treatments } \\
\text { the front straight Strike } \\
\text { skill in tennis }\end{array}$} & \multicolumn{2}{|c|}{$\begin{array}{c}\text { The experimental group } \\
(\mathrm{n}=18)\end{array}$} & \multicolumn{2}{|c|}{$\begin{array}{c}\text { The control group } \\
(\mathrm{n}=17)\end{array}$} & \multirow{2}{*}{$\begin{array}{c}\text { (T) } \\
\text { value }\end{array}$} \\
\cline { 2 - 5 } & Mean & S.D & Mean & S.D & \\
\hline First judge & 9.176 & 0.808 & 7.529 & 1.280 & 4.537 \\
\hline Second judge & 8.882 & 0.696 & 7.00 & 1.060 & 6.211 \\
\hline Third judge & 9.411 & 0.507 & 7.470 & 1.067 & 6.882 \\
\hline The total number of skill & 9.156 & 0.585 & 7.33 & 1.21 & 5.635 \\
\hline
\end{tabular}

Value $(T)$ Indexed at level of significance at $0.05=2.03$, at $0.01=2.72$

The results of Table (5) to the existence of statistically significant differences at the level of significance (0.01) between the telemetric of the control and experimental groups according to the opinion of the referees in the skill of the front straight strike in tennis, and returns the researchers improvement in the level of the performance skills of the experimental group to use as an educational tool and technology that is animation program proposal and who helped in speed of learning and performance of that skill, it is by watching the cartoon character that do a skill within the program and listening to children's verbal explanations of the experimental group was able to visualize the stages of this skill, and then perform well when making dimensional measurements.

This is consistent with the assertion of (28) (33) that the use of modern technology in teaching and learning process have a profound impact in reducing the learning time and improve the level of performance of motor skills learned and the accuracy of learning.
As demonstrated by the results of studies of each of (34), (37) that use animation program had a positive impact and highly effective in teaching and performance of motor skills for activities of various sports, and the animation a positive impact in the education of motor skills for children ages first, and achieve good results when used in all areas. This achieves the fourth hypothesis of the research.

\section{The fifth hypothesis:}

"There is a positive correlation in the measurement of the dimensional perception of motor skill learning and the front straight strike in tennis between the experimental and control groups of children (9-11 years) for the experimental group."

To ensure the validity of the fifth hypothesis was to find the correlation between the degree of dimensional measurement for each of the test scenario and the level of motor skill performance in the skill (under discussion) of the control and experimental groups and illustrated by Table (6). 
Table (6)

Coefficient of correlation between the level of perception and motor skill performance Of skill in telemetric

\begin{tabular}{|l|l|l|l|l|l|}
\hline \multirow{2}{*}{$\begin{array}{c}\text { Statistical treatments } \\
\text { Skill strike the front straight }\end{array}$} & \multicolumn{2}{|c|}{ the perception motor } & \multicolumn{2}{c|}{$\begin{array}{c}\text { motor skill } \\
\text { performance level }\end{array}$} & \multirow{2}{*}{ correlation } \\
\cline { 2 - 5 } & Mean & S.D & Mean & S.D & \\
\hline $\begin{array}{l}\text { The experimental group } \\
(\mathrm{n}=18)\end{array}$ & 8.332 & 1.651 & 9.156 & 0.585 & $0.970^{* *}$ \\
\hline $\begin{array}{l}\text { The control group } \\
(\mathrm{n}=17)\end{array}$ & 7.043 & 0.486 & 7.33 & 1.21 & $0.733^{* *}$ \\
\hline
\end{tabular}

Value $(R)$ Indexed at level of significance at $0.05=0.325$, at $0.01=0.418$

It is clear from Table (6) and a positive correlation function between the dimensional measurement of both perception and motor skill performance level of skill to hit the front straight in tennis, both experimental and control groups for the experimental group.

And returns the researchers of this relationship that the use of animation program and re-display the motor skill more than once gave the children a statement on the relay motor and the sequence of stages of performance, and identify the minutes of skill, all of which helped to recall the correct images of motor skill learned, thus improving the level of performance, as demonstrated by the results of each of the studies (12), (18), (26) that the vision that helps in the speed of motor learning and the accuracy of the performance of motor skills, which confirms the existence of correlation between the level of perception and motor skill performance in various sports activities.

This is in addition to the animation program that has been proposed and used in the search has two attractions and thrill to the front straight strike skill in tennis, raising motivated children to learn in a positive way.

And thus achieved the fifth hypothesis for research.

\section{Conclusions:}

1. Each of the tutorial using the animation and the traditional method a positive impact on children's learning from (9-11) years skill strike straight in front of tennis.

2. Tutorial using animation more positive about the way the traditional perception of motor skill strike the front straight in tennis for children (911 years).

3. Tutorial using animation more positive about the traditional method of learning a skill strike the front straight in tennis for children (9-11 years).

4. Made use of animated tutorial is a positive correlation between perception and motor skill learning strike the front straight in tennis for children (9-11 years).

\section{Recommendations:}

1. Application tutorial using animation to teach children (9-11 years) hit the front straight skill in tennis.

2. Application of educational programs using animation to teach children (9-11 years) tennis skills in basic and advanced.

3. Application of educational programs using animation to teach children (9-11 years) of different sports activities.

4. Interest in the preparation of physical education teachers to use different ways of teaching and modern learning environment to make more positive and help children at the speed of learning.

\section{References:}

\section{Arabic References:}

1. Ibrahim Ahmed Salama (1986): Kinetics and training, the National House for Printing and Publishing, Alexandria.

2. Ahmed Mohammed Abdullah (1995): The effect of the use of educational technology in learning some motor skills and knowledge in basketball, unpublished Ph.D. thesis, Faculty of Physical Education for Girls, Helwan University.

3. Ahmed Mustafa Al Swaify, Ehab Sayed Ismail (1998): a proposed program for the perception of mental and physical learning swimming free and back, the International Scientific Conference, Sports Egyptian and Arabic about the prospects for the World, April, Volume II, Cairo. 
4. Osama kamel rateb (1995): Psychology of sports concepts, applications, House of the Arab Thought, Cairo.

5. Osama kamel rateb (2000): Mental skills training applications in the sports field, House of the Arab Thought, Cairo.

6. Amal Al-Zoghbi (2004): Animation as one of modern technologies in the physical education lesson the first loop of basic education, the Standing Scientific Committee, Tanta University.

7. Ameen Anwar Al-Kholi, Gamal el Shafi'i (2001): Tennis - History - skills, plans - rules of the game, a series of tennis video games, House of the Arab Thought, Cairo.

8. Ayman Mahmoud, Essam El-Din Mohamed (2001): Effectiveness of an educational program using animation on learning disabilities, some of the skills he studied physical education for students with different body styles of the second loop of basic education city of Minya, the number of semi-annual, Faculty of Physical Education, Minia University.

9. Ellen Wadi Farag (1994): Tennis - education, training, evaluation, arbitration, plant knowledge, Alexandria.

10. Rasha Ahmed Mohammed Allam (2005): The impact of a program of mental perception at the level of performance skills of players compulsory kata karate, Master unpublished, Faculty of Physical Education, Tanta University.

11. Sayied Abdel-Maksoud (1986): Theories of the movement, young free Press, Cairo.

12. Abdel Ati Abdel-Fattah elsayied, Khaled Mohammed zyada (2001): The impact of the development of the perception of mental on the accuracy of performance of the transmitter from the top of the jump of $U$ (17) years in volleyball, the International Scientific Conference for Sport and Globalization, Volume I, Faculty of Physical Education for boys, Helwan University.

13. Amr Mohamed Abdel-Razek (2000): The effect of the trampoline and mental visualization to raise the performance level of some of the endings motor vehicle on the balance beam for gymnastics junior, unpublished Ph.D. thesis, Faculty of Physical Education, University of Tanta.
14. Mustafa Hassan Abdel-Rahman (1996): the concept of educational methods and technology, Revival of Islamic Heritage House Publishing, Medina, Saudi Arabia.

15. Mustafa Abdel-Samie et all (1999): Education Technology - Arab Studies, Center for the Book Publishing, Cairo.

16. Mustafa Abdel-Samie et all (2001): Communication and educational tools, the center of the book for publication, Cairo.

17. Mohamed eLarabi Shamoon (2001): Mental training in sports, second edition, the Arab Thought, Cairo.

18. Mohammed Abdel Razek Gomaa (1989): Relationship of motor perception quickly learn and accuracy of performance of certain movements, fencing, Unpublished Master Thesis, Faculty of Physical Education for boys, Alexandria University.

19. Mohammed Abdul Ghani Othman (1994): Motor learning and sports training, home pen, Kuwait.

20. Mohammad Hassan Allawi (1991): Sport and Exercise Psychology, House of Knowledge, Version 7.

21. Mohammad Hassan Allawi (2002): The Psychology of sports training and competition, the Arab Thought House, Cairo.

22. Mohammed wageeh sokar (2001): The impact of a proposed program of mental perception to learn fencing skills and develop the focus of attention and the ability to relax, atheist tenth Conference of Physical Education and Sports between theory and practice, Faculty of Physical Education for boys, Cairo.

23. Mona Mahmoud Mohamed (2000): The effectiveness of multimedia computer-based graphics and animation to teach motor skills, unpublished Ph.D. thesis, Faculty of Physical Education for Girls, Helwan University.

24. Wafiqah Mustafa Salim (2001): Educational Technology and Learning in Physical Education, Part I, First Edition, facility knowledge, Alexandria.

\section{Foreign References:}

25. Baron's (2000): Tennis course volume lessons and training, beaver book, Ontario I, iw, 127 Canada. 
26. Carbone, -J, etall(2002): The effects of brief imagery on free throw shooting performance and concentration style of intercollegiate basket ball players: a Single - Subject - Subject design, International - Sports- Journal- TwistHaven- Conn. 6 92), 60- 67, Total no of pages: 8.

27. Carter- J. E; Kelly, A- E (1997): Using Traditional and Paradoxical imagery interventions with reactant intramural athletes, Sport- Psychologist- (Champaign, - 111) 11 (2), 175- 189, Total no of pages: 15.

28. Cheung. W (1995): How to integrate hypermedia technology in teaching and learning in. Oliver M. wild, (Eds); Precedes of the Australian computers in education conference, Perth, WA.

29. Denhan \& Henry Newton (1992): Using hypermedia technology by animation films to learn some of basketball skills, National center for sports, east Lansing, Tully.

30. Gakson., (1999): Learn tennis in a weekend, Dorling Kindersley limited, London.

31. Guthric, B. McPherson M (1992): An Evaluation of Customized To Computer Assisted Instruction in under Graduate Physical Education, International Conference on
Computer Applications in Sport and physical Education Wingate institute Sport Express.

32. Harris. D-robinson( 1986): The effect of Skill Level on EMG activity during internal and exlernol imagery journal of sport, psychology.

33. Hith (2000): Goolgelcom Newmwdia site go wings Cheung whal Teacher need to know out hypermedia.

34. Maynard (2002): Animation graphics in learning some of handball skills, $\mathrm{R}(\mathrm{Ed})$ in Mealeese Vol.15, Oxford intellect.

35. Michelle Mullen (1999): Teaching by hypermedia with animation graphics in to sports classrooms, Graduate center for sports, Germaine California state University long Beach.

36. Sassen, Timothy (2001): An analysis of secondary school teacher attitudes towards instructional technology use into the context of motivation theory, ph. D. Degree- Loyola University, of Chicago, Diss Abs inte, vol, 5960.

37. Stan Hayward (2001):Computer \& Animation to learn a motivation skills for children in pray school, PHD degree Voi, X1 No.11. 